\title{
Simulating practice to enhance learning for 14-16 year old health and social care students
}

\section{Karen Murrell}

Thames Valley University, UK

\section{Abstract}

This paper will present an evaluation of the use of simulated practice in the education of 14-16 year old students who are interested in pursuing a career in health care. Currently there is much emphasis on the recruitment and retention of the best available candidates into the health and social care professions. However, ensuring that prospective students have a full understanding of the professional and educational requirements of their chosen career is an ongoing challenge. Using simulation in health care education provides an opportunity to practise skills and consider professional issues in a risk-free learning environment that closely resembles the realities of practice. A simulated practice session was developed and piloted with a group of students who were undertaking the first year of the Diploma in Health and Social Care. The simulation session entitled 'Edith's rights' addressed many aspects of practice that were integral to the curriculum. This included: infection control; health and safety in clinical setting; privacy and dignity; nutritional assessment; physical care needs and communication skills. Students' confidence and perception of ability to apply theory to practice were assessed prior to and after the simulation session. Data was also collected following the simulation session about the quality of the learning experience. Analysis of the data demonstrated that simulation can support preparation for practice and assist in the application of theory to practice. Students reported that using simulation in this way had given them a clearer idea of the professional role and educational challenges of the career that they were about to embark on. These findings will have implications for health and social care educators who are considering, or using, simulation to prepare students for entering a health care career.

Keywords: simulated practice; professional practice; nursing. 


\section{Background}

With the current emphasis on recruitment and retention of the best available candidates into health and social care, there is a desire to develop a range of innovative apprenticeship programmes to attract, support and prepare suitable staff for entry to professional training (Darzi, 2008). Academic staff involved with one such apprenticeship programme, the BTEC First Diploma in Health and Social Care for 14-16 year olds delivered in collaboration with Thames Valley University (TVU) in London, decided to introduce simulated practice as part of the learning experience to improve understanding of and preparation for professional practice among the candidates. Supporting students for entry and engaging in higher education $(\mathrm{HE})$ is essential if recruitment and retention is to be effective, as students will have greater understanding of the unique challenges for learning in HE as well as the relevant professional and practice issues (Hilsdon, 2008). This case study outlines the planning and subsequent evaluation of the simulation aspect of the programme, by reviewing the effect on student confidence, student learning and preparation for professional practice.

The examining body for the diploma recommends that all students undertake 50 hours of related work experience during the course to consolidate their learning and enable them to complete practical based assignments. Due to the young age and limited experience of the students, it was considered that preparation for practice using simulation sessions could enhance the subsequent learning within the work placement and contribute to their understanding of professional roles in health and social care. Introducing simulation into the programme also enabled the students to be exposed to a variety of clinical experiences in a controlled and safe environment. The simulations were not seen as a replacement for work experience but rather as a valuable addition which could enhance learning by giving students the opportunity to develop practical skills, put theory taught in the classroom setting into practice, and receive positive and constructive feedback, which is not always possible in a busy workplace.

\section{What is simulation?}

McGaghie (1999) has defined simulation as a person, device or set of conditions made to resemble clinical practice as closely as possible which provide risk-free opportunities to 
practice clinical skills and develop clinical judgement. Students are required to respond to situations as they would in the real environment, usually in real time. Debriefing and feedback on performance are crucial to the process. Application and integration of knowledge, skills and critical thinking are required and students are active participants (McGaghie, 1999).

The use of simulation and simulators has a relatively long history in medical education and more recently it is being considered as a desirable component of education programmes across all health care professions (Darzi, 2008; NMC, 2007). Advantages associated with the use of simulation include: real-time interactive experiences and participation in clinical situations; practice within a safe and controlled environment; outcomes that can be standardised allowing repetition, reliability and reproducibility; experience of a wide variety of scenarios, adaptable to multiple learning strategies and learning styles (Allinier et al., 2006; Issenberg et al., 2005). Another advantage of simulation is that it enables students to practise a variety of skills in an environment where there is no fear of making harmful mistakes, which is supported in a systematic review of simulation in pre-registration nursing (Laschinger et al., 2008).

TVU has a fully equipped simulation centre, which has been designed to simulate health and social care environments and is staffed by nurse educators who are experienced in delivering structured simulation within a range of pre- and post-registration healthcare programmes. Extending the use of simulation to programmes for 14-16 year olds was seen as an ideal opportunity to improve the learning experience for these future preregistration health and social care students as well as promote recruitment of better prepared candidates in the future.

\section{Developing the scenario}

The next stage of the project was to map the initial simulation to the learning outcomes of the programme. This identified several areas that the simulations could be based around: communication, infection control, care value base and care needs. A simulation session was prepared that focussed on the care value base and also incorporated communication skills, infection control, health and safety in practice, privacy and dignity (see outline of scenario below). 


\section{The simulation scenario - Edith's rights}

The students spent the term learning about the care value base and their learning had been checked in a variety of ways so the tutors were confident that they understood the concepts and values involved. They had also covered communication skills and infection control. It was decided therefore to test the students' knowledge in this simulation by asking them to take the part of a healthcare worker in a nursing home so they were able to demonstrate the practical application of the values.

\section{Student notes for Edith's rights}

'Edith Smith is an 85 year old lady who is a resident in the nursing home where you work as a care worker. You have just come on duty when you hear her calling you from the day room. You go to see her and she has been sick and is still feeling very unwell and fears she will be sick again. She is very upset and agitated. You are a Health Care Assistant and your responsibility now is to care for Edith and maintain her rights in accordance with the Care Value Base. Elsie is Edith's friend who sits next to her in the day room. Elsie is very concerned that Edith is sick and wants to know what is going on. She keeps asking you questions about Edith and wanting to help you. She is very concerned that Edith will miss her lunch as she thinks Edith needs to eat something'.

The students worked in pairs and were expected to assist Edith to clean up and change her clothes, whilst considering what they had been taught about infection control. They were also expected to use the screens to give her privacy. They were expected to observe health and safety procedures in relation to cleaning the vomit off the floor. When challenged by Elsie they should have considered confidentiality regarding Edith's condition.

In order to evaluate the effectiveness of the simulation, self-assessment of confidence using a 5 point Likert scale (Figure 1) was measured before and after the session (see Figure 2 for table of results). Student perception of preparation for practice was also evaluated after the session. Data from the simulation session was also submitted as evidence to the internal verifier as part of the assessment for the unit. Student reflections following the simulation sessions were recorded in Individual Learning Plans to inform future learning in practice placements. 
Figure 1. Confidence questionnaire for Edith's rights.

\begin{tabular}{|c|c|c|c|c|c|}
\hline & $\begin{array}{l}\text { Strongly } \\
\text { disagree }\end{array}$ & $\begin{array}{l}\text { Somewhat } \\
\text { disagree }\end{array}$ & $\begin{array}{l}\text { Neither } \\
\text { agree nor } \\
\text { disagree }\end{array}$ & $\begin{array}{l}\text { Somewhat } \\
\text { agree }\end{array}$ & $\begin{array}{l}\text { Strongly } \\
\text { agree }\end{array}$ \\
\hline \multicolumn{6}{|l|}{$\begin{array}{l}\text { I feel confident that I } \\
\text { know how to show my } \\
\text { patient respect }\end{array}$} \\
\hline \multicolumn{6}{|l|}{$\begin{array}{l}\text { I feel confident that I } \\
\text { know how to maintain } \\
\text { my patient's dignity }\end{array}$} \\
\hline \multicolumn{6}{|l|}{$\begin{array}{l}\text { I feel confident that I } \\
\text { know how to treat my } \\
\text { patient as an individual }\end{array}$} \\
\hline \multicolumn{6}{|l|}{$\begin{array}{l}\text { I feel confident that I } \\
\text { know how to maintain } \\
\text { my patient's privacy }\end{array}$} \\
\hline \multicolumn{6}{|l|}{$\begin{array}{l}\text { I feel confident that I } \\
\text { know how to protect my } \\
\text { patient from harm }\end{array}$} \\
\hline \multicolumn{6}{|l|}{$\begin{array}{l}\text { I feel confident that I } \\
\text { know how to give my } \\
\text { patient access to } \\
\text { information about } \\
\text { themselves }\end{array}$} \\
\hline \multicolumn{6}{|l|}{$\begin{array}{l}\text { I feel confident that I } \\
\text { can communicate with } \\
\text { my patient using their } \\
\text { preferred form of } \\
\text { communication }\end{array}$} \\
\hline \multicolumn{6}{|l|}{$\begin{array}{l}\text { I feel confident that I } \\
\text { can promote my } \\
\text { patient's independence }\end{array}$} \\
\hline \multicolumn{6}{|l|}{$\begin{array}{l}\text { I feel confident that I } \\
\text { can help my patient } \\
\text { make choices about } \\
\text { their care }\end{array}$} \\
\hline \multicolumn{6}{|l|}{$\begin{array}{l}\text { I feel confident that I } \\
\text { can promote my } \\
\text { patient's rights }\end{array}$} \\
\hline \multicolumn{6}{|l|}{$\begin{array}{l}\text { I feel confident that I } \\
\text { can effectively } \\
\text { communicate with my } \\
\text { patients }\end{array}$} \\
\hline $\begin{array}{l}\text { I feel confident that I } \\
\text { can maintain my } \\
\text { patient's confidentiality }\end{array}$ & & & & & \\
\hline
\end{tabular}


Figure 2. Students' self-rating of confidence.

Students' Self-Rating of Confidence in Undertaking Ediths Right Care Values Before and After Simulation

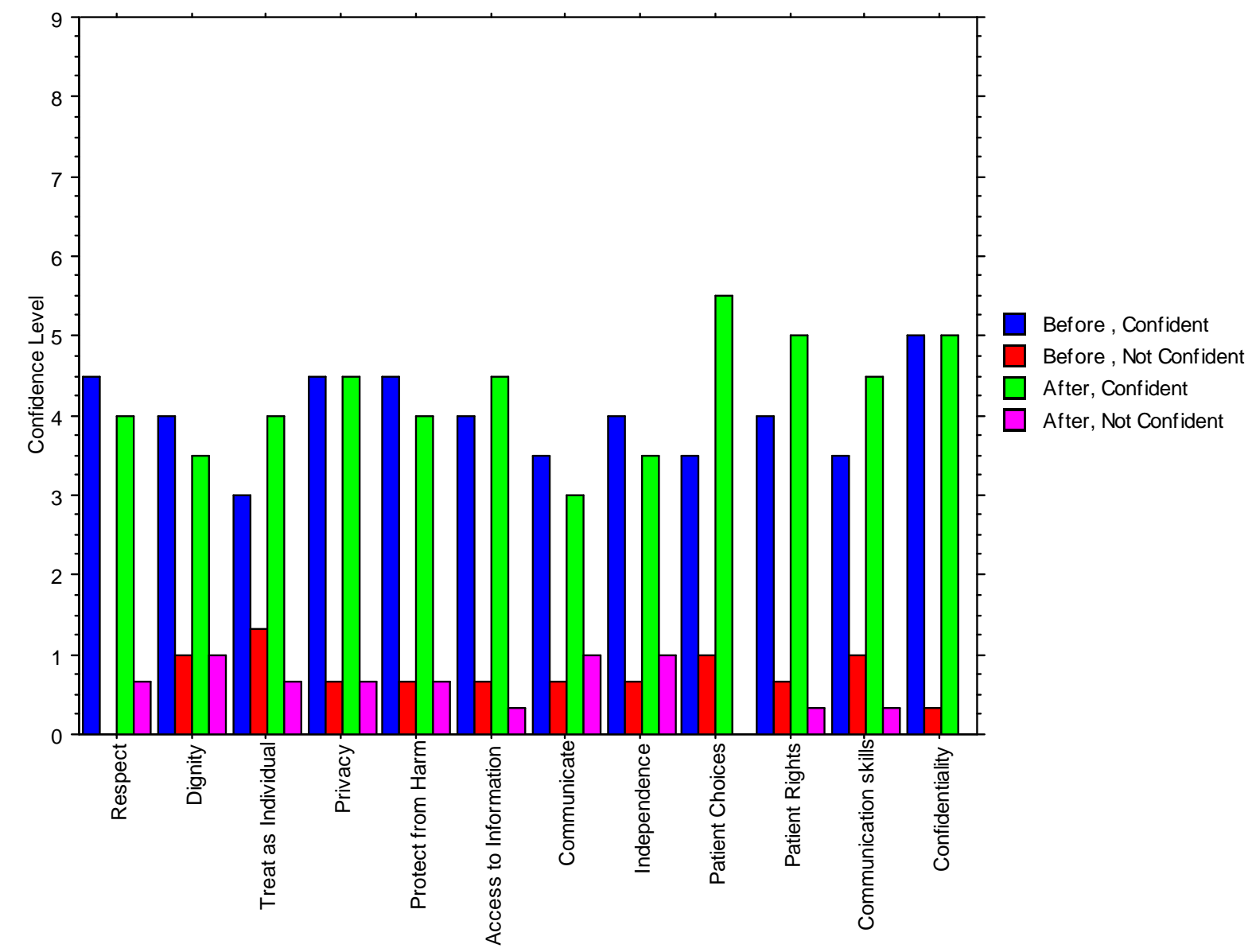

\section{Evaluation}

The findings from the fourteen sets of quantitative responses fell into two key areas: supporting and promoting learning and putting theory into practice.

\section{Supporting and promoting learning}

Although the results do not prove that there has been an increase in learning, four of the fourteen responses commented specifically regarding the positive effects on their learning. For some it confirmed for them what they already knew:

It was good to see that I know how to keep confidentiality.

It was good to practise calming a patient, I was surprised that I could do it. 
Others identified that participating in simulation could help them with future learning:

I can now see what I need to learn.

It would be good to have more time after session to plan our learning needs for next time.

'It would be good if we could watch each other so we could see how others do it we could learn more.

Three of the fourteen students wanted to watch each other next time, which we can try to do, although Prescott and Garside (2009) report that not all students appreciate this.

\section{Theory to Practice}

Whilst the simulation is not the same as 'real' practice experience, it was hoped that the experience would prepare the students effectively for their subsequent placement. Eleven of the fourteen students reported that they felt better able to link theory to practice following the session:

I will always remember the importance of cleanliness.

Reminded me about communication and how to talk to Edith.

For some the realism of the simulation helped them to link theory to practice:

Making it so real so we know what it would be like.

\section{Discussion}

Following the simulation some students reported feeling less confident in their ability to link theory to practice. A possible reason for this situation is that when faced with the reality of having to apply theory to practice, most students realised that it was not as easy as they thought. This suggests that the students had an increased awareness of the practical 
difficulties inherent in applying theory to practice and is supported by the findings of Moule et al. (2008) who found that simulation is shown to enable students to demonstrate ability to apply learning into practice.

One area where the group reported feeling they had lost most confidence following the simulation was in their ability to maintain the patient's privacy and dignity. This could be because students were unsure of how to do this due to inexperience or could have been because the patient's situation was undignified and the students may not have known how to cope with it. Several of the students were aware that they should have used the screens to give Edith privacy but didn't do so; this could have been nervousness on the part of the student or unfamiliarity with the equipment.

In the case of confidentiality, the post-simulation drop in confidence could have been because the majority of the students unfortunately made the mistake of telling Edith's friend what was wrong with her. Interestingly all the students who did this knew they had acted inappropriately and commented on what they would do differently next time as part of the debriefing. Even negative effects of the simulation experience can be turned into positive ones by sensitive and supportive feedback (Nicol, 1999).

Following the simulation, whilst playing the part of the carer, some students reported feeling nervous and anxious. This was partly due to the unfamiliarity of the experience. However, they also commented on how much they enjoyed it and how they felt they were able to identify the care values from participating in the simulation. This finding is also identified by Dahl (1984) who argues that learning through simulation is exciting and enjoyable and therefore the retention of information is greater.

Although the students were fully briefed regarding the simulation and the staff felt they had covered the learning adequately prior to the session, some students felt they would have benefitted from more time in the simulation centre prior to this session. This may have reduced anxiety levels and given them more opportunity to become familiar with the equipment and surroundings. The results may also not truly reflect the students' confidence as the format of the questionnaires was unfamiliar to them and, due to their age, they were inclined to tick the answers that they thought the tutors wanted to see rather than how they actually felt. This could have possibly been avoided if the questionnaires had been anonymous throughout the entire process. Another limitation of 
the pilot evaluation was the small number of students included and the subjective nature of their feedback.

\section{Conclusion}

This evaluation set out to explore the use of simulation for 14-16 year old health and social care students in relation to transferring theory into practice and developing an understanding of the professional role. The detailed feedback from the students suggests the cohort enjoyed the experience of the simulation and demonstrated application of theory to practice. Although for some participating in the simulation decreased their confidence, they were able to participate in a safe environment and then reflect on this in a structured way, therefore learning from the experience. As a result of this positive evaluation discussions will continue in collaboration between the university and local schools and colleges in relation to increasing the use of simulation in this programme and others that are offered to this age group.

The potential benefits of introducing simulation into this programme for 14-16 year olds that are interested in careers in health and social care, are that students taught this way may have a greater understanding of the nature of health and social care professions and the use of evidence to support practice. Following this successful simulation session, plans have been made to increase simulation with this student group (and those in a similar age group), by identifying and planning appropriate opportunities across all relevant programmes with secondary school and further education (FE) colleagues. This could help to improve recruitment, progression and subsequent retention of appropriate students into health and social care professions, and is thus entirely congruent with the overall objectives behind the 14-16 year old diplomas.

The simulation was a far better means of teaching health care than power point presentations like other unis. If I was going into health care I would come here because you learn so much about health and safety in clinical practice. (A college student after exposure to the simulation) 


\section{References}

Allinier, G., Hunt, B., Gordon, R. and Harwood, C. (2006) 'Effectiveness of intermediate fidelity simulation training technology in undergraduate nursing education', Journal of Advanced Nursing, 54(3), pp. 359-369.

Dahl, J. (1984) 'Structured experience: a risk free approach to reality based learning', Journal of Nursing Education, 23(1), pp. 34-37.

Darzi, A. (2008) High quality care for all: NHS stage review final report. London: Department of Health.

Hilsdon, J. (2008) A contribution to the Innovative, University, Science and Skills Committee Inquiry: 'Students and Universities' from the Association for Learning Development in Higher Education (ALDinHE). University of Plymouth. Available at: www.aldinhe.ac.uk/Students and Universities Inquiry ALDinHE submission.pdf (Accessed: 23 March 2011).

Issenberg, S., McGaghie, W., Petrusa, E., Lee, G. and Scalese, R. (2005) 'Features and uses of high-fidelity medical simulations that lead to effective learning: a BEME systematic review', Medical Teacher, 27(1), pp. 10-28.

Laschinger, S., Medves, J., Pulling, C., McGraw, R., Waytuck, R., Harrison, M.B. and Gambeta, K. (2008) 'Effectiveness of simulation on health professional students' knowledge, skills, confidence and satisfaction', International Journal of Evidence Based Healthcare, 6(3), pp. 278-302.

McGaghie, W. (1999) 'Simulation in professional competence assessment: basic considerations', in Takien, A., McGuire, C. and McGaghie, W. (eds.) Innovative simulations for assessing professional competence. University of Illinois, Chicago: Department of Medical Education, pp. 7-22.

Moule, P., Wilford, A., Sales, R. and Lockyer, L. (2008) 'Student experiences and mentor views of the use of simulation for learning', Nurse Education Today, 28(7), pp. 790797. 
Nicol, M. (1999) 'Is simulation the answer?', in Nicol, M. and Glen, S. (eds.) Clinical skills in nursing, the return of the practical room? Basingstoke: Macmillan, pp. 13-24.

Nursing and Midwifery Council (2007) Simulation and practice learning project. London: NMC.

Prescott, S. and Garside, J. (2009) 'An evaluation of simulated practice for adult branch students', Nursing Standard, 23(22), pp. 35-40.

\section{Author details}

Karen Murrell RGN MSc is a freelance teacher in Health and Social Care at Farnborough College of Technology and Central College London. Karen was formerly Head of Simulation at Thames Valley University. 